\title{
Física Quântica no ensino médio: uma análise bakhtiniana de enunciados em livros didáticos de Física aprovados no PNLDEM $2015^{+*}$
}

\author{
Nathan Willig Limal \\ Doutorando - UFRGS \\ Fernanda Ostermann ${ }^{2}$ \\ Claudio Jose de Holanda Cavalcanti ${ }^{3}$ \\ Instituto de Física - UFRGS \\ Porto Alegre - RS
}

\section{Resumo}

Neste trabalho, apresentamos uma análise dos enunciados sobre Física Quântica presentes nas quatorze obras de Física aprovadas pelo Plano Nacional do Livro Didático do Ensino Médio em 2015. Utilizamos a Filosofia da Linguagem de Mikhail Bakhtin como referencial teórico metodológico com o objetivo de avaliar quais são as abordagens utilizadas pelos autores para introduzir a Física Quântica, quais os conceitos apresentados e quais visões epistemológicas são veiculadas nessas apresentações. Nossos resultados indicam que todos os livros optam por uma abordagem histórica, restringindo-se à velha Física Quântica. Os conceitos apresentados e a sequência de apresentação em trezes livros são praticamente idênticos aos encontrados em livros de Física Moderna utilizados no ensino superior, cometendo, inclusive, os mesmos erros historiográficos. Isso sugere que os autores veiculam os enunciados que aprenderam em suas formações sem um aprofundamento crítico. Todos os livros apresentam uma escolha lexical que pode ser associada à epistemologia positivista e treze livros apresentam uma estrutura composicional que se alia ̀̀ mesma visão, a qual é considerada epistemologicamente ultrapassada. A apresentação reducionista presente nos livros didáticos atuais indica a

\footnotetext{
${ }^{+}$Quantum Physics in high school: a bakhtinian analysis of Physics textbooks approved at PNLDEM2015

* Recebido: fevereiro de 2017.

Aceito: junho de 2017.

1 E-mail: lima.nathan@gmail.com

2 E-mail: 00008943@ufrgs.br

${ }^{3}$ E-mail: claudio.cavalcanti@ufrgs.br
} 
necessidade de se avançar em abordagens de Física Quântica que rompam com a perspectiva positivista hegemônica.

Palavras-chave: Física Quântica; Livro Didático; Bakhtin.

\begin{abstract}
In this work we present an analysis of Quantum Physics texts present in the fourteen books approved by the National Textbook Plan for High School in 2015. We used Bakhtin's Philosophy of Language as a theoretical and methodological framework. Our aim was to evaluate which approaches are used by textbook authors to introduce Quantum Physics as well as which concepts and epistemological views are stated in these presentations. Our results show that all books present a historical approach, limited to the Old Quantum Physics. Concepts and presentation sequences are very similar to what can be found in Modern Physics undergraduate textbooks, containing even the same historiographic mistakes. This suggests that authors state what they have learned during undergraduate courses without any further critical review. All books present lexical choice that can be associated to positivist epistemology, and thirteen books present a compositional structure allied to the same view, which is considered epistemologically outdated. The reductionist textbook presentation indicates the necessity of breaking up with the hegemonic positivist perspective.
\end{abstract}

Keywords: Quantum Physics; Textbook; Bakhtin.

\title{
I. Introdução
}

Física Quântica (FQ) é um tópico de extrema relevância presente em currículos de licenciatura e bacharelado em Física. Além de ser um marco na formação acadêmica e um símbolo da cultura da Física, os temas abordados em disciplinas de FQ estão mais próximos das teorias e técnicas utilizadas na pesquisa contemporânea do que os assuntos vistos nas disciplinas iniciais (JOHANSSON et al., 2016).

Reconhecendo a importância dessa teoria para a comunidade científica e para a sociedade, a literatura vem apontando a necessidade da sua abordagem, também, no Ensino Básico (SILVA; ALMEIDA, 2011; TELICHEVSKY, 2015), o que traz como benefício a aproximação entre o conhecimento escolar e os debates da academia. Além disso, a terminologia da FQ permeia o discurso fora das universidades (HILGER; MOREIRA, 2012) - o que reitera a necessidade de uma formação científica e crítica em FQ. 
Não existe consenso, entretanto, sobre qual seria a melhor abordagem para a introdução desse tópico seja em nível básico ou superior. É possível identificar três principais caminhos (OSTERMANN; MOREIRA, 2000): a primeira possibilidade é partir das limitações dos modelos clássicos para chegar à teoria quântica (escola espanhola de GIL et al. (1988)); a segunda possibilidade é partir de uma apresentação direta do formalismo quântico, evitando-se analogias clássicas (escola alemã de Fischler e Lichtfeldt (1992), e, por fim, pode-se apenas apresentar alguns tópicos introdutórios e genéricos para gerar familiarização dos alunos com o assunto (ARONS, 1990). Países como Portugal, Espanha, Itália e Finlândia seguem, em seus currículos escolares, a abordagem espanhola, enquanto que Reino Unido, Dinamarca, Suécia, Canadá e Austrália apresentam a FQ pelo problema de fenda dupla (LOBATO; GRECA, 2005).

Deve-se ter em mente que, em toda apresentação de tópicos de Física, adote ela uma abordagem histórica, postulacional ou fenomenológica, veicula-se, implícita ou explicitamente, uma determinada visão de ciência, isto é, apresenta-se uma definição do que é ciência, qual sua validade, qual seu objetivo, como se dá a sua prática. É importante que, em uma apresentação didática, tenha-se clareza de qual é a visão de ciência veiculada, visto que a literatura (MCCOMAS et al.,1998; MATHEWS, 1995) tem apontado, há mais de duas décadas, a importância de trazer o debate epistemológico para dentro da sala de aula.

No Brasil, a maioria dos professores de Física não é formada em Física (SANTOS; CURI, 2012). Essa deficiência, além de outros fatores como a desvalorização da carreira docente, faz com que o livro didático ganhe um papel extremamente relevante no contexto do Ensino Básico, pois ele não somente pauta a estruturação da disciplina de Física bem como é a fonte dos enunciados sobre ciência, influenciando, portanto, de forma substancial, a construção das visões epistemológicas dos alunos de Ensino Médio (EM).

Há mais de uma década, os livros didáticos de Física utilizados nas escolas públicas são aqueles aprovados pelo Plano Nacional do Livro Didático do Ensino Médio (PNLDEM), cuja última edição ocorreu em 2015. No entanto, há pouca produção acadêmica sobre FQ em livros didáticos do EM, sendo possível encontrar um só artigo sobre o tema (em publicações brasileiras classificadas como A1 e A2 pelas CAPES - classificação de 2014), o qual traz a visão dos autores sobre a inserção de Física Moderna em seus livros aprovados pelo PNLDEM 2012 (DOMINGUINI, 2012). Trabalhos publicados em periódicos não classificados nos extratos superiores mostram que a Física Moderna vem ganhando maior importância nos livros didáticos aprovados no PNLDEM (DOMINGUINI, 2011; MAXIMIANO; CARDOSO; DOMINGUINI, 2012a, MAXIMIANO; CARDOSO; DOMINGUINI, 2013), e indicando ainda que a apresentação se restringia à velha Física Quântica no PNLDEM 2012 (MAXIMILIANO; CARDOSO; DOMINGUINI, 2012b).

A maioria das publicações existentes sobre Pesquisa em Ensino de FQ refere-se à bibliografia de consulta para professores, conforme já apontaram Pereira e Ostermann (2009). Apesar disso, nos últimos anos, tem aumentado o número de propostas implementadas em sala 
de aula, principalmente para o Ensino Superior, o que engloba a construção de unidades didáticas (GRECA; MOREIRA; HERSCOVITZ, 2001); e o uso de softwares para mediação do ensino - Sales et al. (2008) utilizaram um programa para o cálculo da constante de Planck; Pereira, Ostermann Cavalcanti (2012) utilizaram um Interferômetro Virtual de Mach-Zehnder para discutir a dualidade onda-partícula e Trindade, Filhoais e Gil (2005) usaram um software para representação de orbitais atômicos. Com relação à implementação da FQ no Ensino Médio, Hiegler e Girebler (2013) apresentaram a aplicação e avaliação de uma unidade didática sobre a nova FQ e Pegliarini e Almeida (2016) apresentaram uma proposta de leitura de textos de cientistas sobre o início da FQ.

Reconhecendo a necessidade de se aprofundar a pesquisa em Ensino de FQ no Ensino Médio, principalmente, em relação a questões relacionadas a implementações pedagógicas em sala de aula e identificando o livro didático como um componente importante da aula de FQ, o objetivo principal desse trabalho é fazer uma análise bakhtiniana (BAKHTIN, 2016) dos enunciados de FQ presentes nos catorze livros aprovados no Plano do Nacional do Livro Didático de 2015. Com isso, pretende-se responder às seguintes perguntas de pesquisa: quais constructos (conceitos, teorias, afirmações) são privilegiados e quais abordagens (espanhola, americana ou alemã) são adotadas pelos livros didáticos? Como os elementos do enunciado (tema, estrutura composicional e estilo) são empregados para veicular uma visão de ciência? Como essas escolhas dialogam com o paradigma educacional proposto pelo Plano Nacional do Livro Didático e com as pesquisas na área de Ensino de Física?

\section{Referencial teórico-metodológico: A Filosofia da Linguagem de Bakhtin}

Esse trabalho apresenta uma análise qualitativa fundamentada na Filosofia da Linguagem de Mikhail Bakhtin, que se caracteriza por analisar os processos de comunicação discursiva em sua ocorrência concreta, isto é, no evento social da interação verbal; e não engessados em uma forma determinada pelas regras gramaticais: Ela (a linguagem) é um produto da vida social, a qual não é fixa nem petrificada: a linguagem encontra-se em um perpétuo devir e seu desenvolvimento segue a evolução da vida social (VOLOSHINOV, 1981, p.1). Essa visão da linguagem faz a teoria bakhtiniana contrastar com as diferentes teorias linguísticas que lhe eram contemporâneas, nas quais a linguagem era vista ou como fruto da expressão individual livre ou como materialização do sistema abstrato da língua (BAKHTIN, 2006).

Para Bakhtin, toda expressão linguística é voltada ao outro, mesmo quando esse outro se encontra fisicamente ausente. Qualquer discurso tem sua estrutura composicional e estilo elaborados no formato de um diálogo. Quando um palestrante faz um discurso, por exemplo, ele espera causar uma certa reação em seus interlocutores, seja de concordância, espanto ou interesse. Mesmo que a plateia não responda verbalmente imediatamente, cada ouvinte terá uma reação que resultará em uma resposta, ainda que essa seja proferida apenas mentalmente. Por isso, embora, do ponto de vista externo, se presencie um monólogo, o processo comunicativo está se dando na forma de um diálogo. 
Podemos, também, reconhecer que mesmo o discurso interno, totalmente privado, resguarda as características estilísticas de um diálogo. Quando se está prestes a tomar uma decisão, esse aspecto fica ainda mais visível - o sujeito realiza um debate interno, em que vozes com ideias opostas se contrapõem até chegar a uma conclusão. Nessa situação, o sujeito cria um ouvinte virtual (cuja "personalidade" representa as ideias predominantes do grupo social em que está inserido) com quem dialoga. Esse caráter dialógico do discurso, isto é, sua inevitável orientação a alguém que seja capaz de compreender e dar uma resposta (real ou virtual) é chamado, na teoria bakhtiniana, de orientação social do discurso (VOLOSHINOV, 1981). Em outras palavras, podemos falar que todo discurso apresenta direcionalidade (SOUZA; REZENDE; OSTERMANN, 2016), isto é, o discurso é sempre direcionado a um interlocutor imaginado, que pode coincidir parcialmente com um interlocutor real (VENEU; FERRAZ; REZENDE, 2015). Dessa forma, podemos entender que o discurso é sempre dialógico, sempre realizado dentro de uma interação social com o objetivo de provocar uma resposta e, portanto, nunca é neutro (BAKHTIN, 2006; 2016).

Para demarcar a diferença de sua análise da linguagem em sua realização concreta com relação à análise puramente linguística, Bakhtin propõe o conceito de enunciado como a unidade do processo de comunicação discursiva, em oposição a unidades gramaticais tradicionais, como a oração ou a palavra, por exemplo. Um enunciado não tem correspondência direta com unidades gramaticais e pode ser desde uma resposta monossilábica em um diálogo (somente no caso em que essa resposta expresse toda ideia do locutor e permita o surgimento de uma resposta) até um romance completo. O que determina os limites do enunciado é a situação concreta em que ocorre (tal aspecto será abordado detalhadamente na sequência do texto).

Ainda, devemos notar que cada enunciado é concreto (existe apenas em um evento da interação social) e único (apresenta aspectos estilísticos que são próprios do autor), mas seu conteúdo temático, seu estilo (seleção de recursos lexicais, fraseológicos e gramaticais) e sua construção composicional refletem as condições específicas e as finalidades do campo de atividade humana em que são realizados (BAKHTIN, 2016). Ao escrever um artigo científico para ser submetido a uma revista de física teórica, por exemplo, um sujeito deverá escolher um tema que seja de relevância àquela comunidade científica, deverá usar predominantemente uma linguagem técnica, impessoal e objetiva, e deverá construir o artigo seguindo uma sequência esperada (introdução, objetivos, métodos, resultados e conclusões), sendo permitida uma pequena margem para variações de estilo individual. Se o mesmo sujeito decidir escrever um texto de cunho religioso, o tema, o estilo e a construção composicional terão outras características. Dessa forma, podemos dizer que cada campo de utilização da língua elabora seus tipos relativamente estáveis de enunciados, os quais são denominados gêneros do discurso (BAKHTIN, 2016).

Portanto, nenhum enunciado pode ser considerado uma combinação absolutamente livre da língua (BAKHTIN, 2016), pois, uma vez escolhido o gênero do discurso - o enunciado 
estará restringido em suas possibilidades. Essas restrições aparecem porque o sujeito não constrói seu enunciado a partir de um vazio absoluto, mas o faz a partir de enunciados anteriores que já presenciou.

Ademais, todo falante é por si mesmo um respondente em maior ou menor grau: porque ele não é o primeiro falante, o primeiro a ter violado o eterno silêncio do universo, e pressupõe não só a existência do sistema de língua que usa mas também de alguns enunciados antecedentes - dos seus alheios - com os quais o seu enunciado entra nessas ou naquelas relações (baseia-se neles, polemiza com eles, simplesmente os pressupõe já conhecidos do ouvinte). Cada enunciado é um elo na corrente complexamente organizada de outros enunciados (BAKHTIN, 2016, p. 26).

Assim, um enunciado está sempre em diálogo com enunciados anteriores, característica denominada de responsividade (SOUZA; REZENDE; OSTERMANN, 2016) e que é responsável, em parte, pela expressão do próprio discurso bem como pelos recursos linguísticos utilizados. De forma mais explícita, quando fazemos uma citação direta, percebemos a inserção de enunciados alheios em nosso próprio enunciado; mas, de forma mais sútil, qualquer enunciado é permeado por uma série de palavras e tonalidade dialógicas de outros autores, e, por isso, o enunciado é representado como a confluência de ecos distantes que reverberam no discurso do autor. Bakhtin (2016) descreve esse fenômeno em termos de veiculação de vozes, isto é, todo enunciado veicula vozes de enunciados precedentes. Devemos ter em mente que voz é a personalidade falante ou consciência falante (WERTSCH, 1991). Assim, em um enunciado, podemos perceber a veiculação de diferentes vozes, com diferentes visões ontológicas, políticas e epistemológicas. Por conta disso, entendemos que a orientação social do discurso se dá de forma dupla: primeiro, porque é voltado ao outro (direcionalidade); e, segundo, porque é motivado pelos discursos de terceiros (responsividade).

Entendendo esse quadro geral da Filosofia da Linguagem de Bakhtin, precisamos, ainda, aprofundar a identificação e a estruturação de enunciados, para que possamos utilizar os conceitos da teoria dentro de um método de análise de enunciados.

\section{II.1 Identificação de Enunciados}

Como mencionado, a unidade da comunicação discursiva e, portanto, o objeto de nossa análise são os enunciados concretos. Souza (2002) identifica três particularidades constitutivas do enunciado concreto: alternância dos sujeitos falantes, acabamento específico do enunciado (conclusibilidade) e relação do enunciado com o próprio locutor e com os outros parceiros da comunicação verbal (expressividade).

Cada enunciado deve ser entendido como um elo na cadeia da comunicação discursiva, sempre respondendo a enunciados anteriores e se direcionando aos outros sujeitos para suscitar novos enunciados. Portanto o que delimita sua estrutura é justamente, como num diálogo, a alternância dos sujeitos falantes. 
Desse modo, a alternância dos sujeitos do discurso, que emoldura o enunciado e cria para ele a massa firme, rigorosamente delimitada dos outros enunciados a ele vinculados, é a primeira peculiaridade constitutiva do enunciado como unidade da comunicação discursiva, o que o distingue da unidade da língua (BAKHTIN, 2016, p. 35).

A segunda particularidade de um enunciado (intimamente ligada à primeira) é a conclusibilidade, cujo principal critério de reconhecimento se dá pela possibilidade de responder ao enunciado. Para que um enunciado possa ser respondido ele deve exprimir "tudo" que o locutor quer dizer (BAKHTIN,2016). Para que essa plenitude acabada do enunciado seja atingida, três elementos devem estar presentes na totalidade orgânica do enunciado: a exauribilidade semântica-objetal, o projeto de discurso do falante e as formas típicas da composição e do acabamento do gênero do discurso.

Por fim, a terceira particularidade de um enunciado é sua expressividade, isso é, a relação subjetiva emocionalmente valorativa entre o sujeito e o objeto do discurso. No discurso oral, essa expressividade é facilmente reconhecida na tonalidade adotada pelo locutor. Em um texto, conseguimos imaginar a tonalidade expressa a partir da construção composicional e do contexto em que o enunciado se encontra. Essa expressividade indica a relação valorativa não só entre o objeto e o locutor isoladamente, mas também reflete o valor compartilhado pelos outros sujeitos que são participantes do gênero do discurso em questão.

Esses três aspectos (alternância dos sujeitos, conclusibilidade e expressividade) caracterizam um enunciado e o diferenciam de elementos gramaticais da língua. Eles servem, portanto, primeiramente como balizadores para que possamos identificar os limites de um enunciado (principalmente a partir dos dois primeiros aspectos) e a relação de valor que esse guarda com relação ao gênero do discurso a que pertence. Uma vez feito isso, podemos avançar na análise do enunciado, entendendo sua estruturação.

\section{II.2 Estruturação de enunciados}

Todo enunciado é composto por uma parte verbal e uma parte extra-verbal, não exprimida, mas subentendida (VOLOSHINOV, 1981). Se não considerarmos a dimensão extra-verbal do enunciado, a dimensão verbal não pode ser compreendida: imagine, por exemplo, uma expressão verbal como “Que maravilha!” Essa expressão pode adotar diferentes sentidos dependendo da situação em que está sendo expresso, podendo indicar felicidade (após o sujeito receber um presente de que gostou), ironia (após o sujeito ficar sabendo que vai receber visita de alguém com quem não simpatiza), descontentamento (após o sujeito derrubar café sobre o seu livro).

Uma análise de discurso passa, portanto, inevitavelmente por um profundo reconhecimento do contexto extra-verbal do enunciado, que pode ser entendido como sendo formado pela situação (efetiva realização na vida concreta, de uma determinada formação, de uma determinada variação da relação de comunicação social) e pelo auditório (aqueles que fazem parte 
da situação) cuja peso social e hierárquico aparece expresso naquilo que chamamos, anteriormente, de orientação social do enunciado (VOLOSHINOV, 1981).

A situação pode ainda ser entendida como constituída por três elementos: o espaço e o tempo do evento, o objeto ou o tema do enunciado, e a posição dos interlocutores diante do fato. Essa situação pode ser entendida em três níveis: o primeiro é o contexto direto, o diálogo imediato, presencial, o segundo é contexto social e do tempo histórico, e o terceiro é contexto social e cultural mais amplo e do "grande tempo" (VENEU; FERRAZ; REZENDE, 2015) .

Assim, quando analisamos um enunciado, temos que levar em conta o auditório e a situação nesses três níveis, para que possamos compreendê-lo de uma forma mais profunda. Ao avaliar um texto, por exemplo, devemos identificar para quais outros enunciados o autor responde (o que demanda não somente conhecer o contexto extra verbal imediato, mas o contexto social mais amplo, como a formação do autor). Além disso, devemos identificar a quem o autor direciona o seu discurso, quem são os membros do seu suposto auditório. Quais as posições o autor presume que o auditório vai adotar? Qual o conhecimento que o autor supõe que o auditório já possua? Qual resposta ele quer produzir?

As respostas a todas essas perguntas aparecem atadas à inteireza orgânica do enunciado concreto - o gênero do discurso, o tema, o estilo, a estrutura composicional, todos estão vinculados às intenções do locutor bem como à relação que ele guarda com o auditório, com a situação e ao valor que atribui ao objeto do enunciado e não podem ser analisados isoladamente. Na próxima seção apresentaremos um dispositivo que viabilize o uso dos conceitos da Filosofia da Linguagem em um método de análise de enunciados.

\section{Dispositivo analítico Bakhtiniano detalhado}

Veneu, Ferraz e Rezende (2015) apresentaram um dispositivo para análise de enunciados, descrito em quatro etapas. Partimos dessa ideia detalhando a quarta etapa (análise do enunciado) explicitando os conceitos da Filosofia da Linguagem que utilizamos em nossa estratégia metodológica. Os quatro passos do dispositivo analítico são os seguintes:

\section{III.1 Identificação do enunciado}

Os critérios principais que utilizamos para demarcação dos limites do enunciado são a alternância de locutores e a conclusibilidade, isto é, a possibilidade de responder ao enunciado, a qual passa, necessariamente pela exauribilidade semântica-objetal.

\section{III.2 Leitura preliminar do enunciado}

Na primeira leitura dos enunciados, identificamos como que a Física Quântica é apresentada nos livros didáticos: qual abordagem é utilizada e quais acontecimentos históricos, ideias, teorias e experimentos são privilegiados no processo de enunciação. 


\section{III.3 Descrição do contexto extraverbal}

Fizemos uma pesquisa sobre a formação acadêmica de todos os autores bem como sua participação na comunidade acadêmica do Ensino de Física e de Ciências Exatas e da Terra com o intuito de compreender com que outros enunciados os autores dialogam em suas obras. Além disso, analisamos o edital do PNLDEM 2015 que se configura como um elemento importante do contexto extra-verbal comum a todos os autores.

\section{III.4 Análise Bakhtiniana do enunciado}

A última etapa do dispositivo analítico consiste em articular os elementos linguísticos (escolha lexical, sintaxe, estilo, construção composicional, unidade temática, relação com o falante/outros participantes), o contexto extraverbal e os conceitos bakhtinianos envolvidos para responder às questões de pesquisa. No caso dessa pesquisa, elaboramos um roteiro de análise que consiste nas seguintes perguntas sequenciais, que conduzem gradualmente ao entendimento do texto e às respostas das questões de pesquisa. 1) Com qual gênero do discurso estamos lidando? 2) A partir da definição do gênero do discurso e do conhecimento do contexto extraverbal, podemos inferir qual é o auditório do enunciado, isto é, para quais supostos interlocutores o autor fala? 3) Qual o tema do enunciado? 4) A partir do conhecimento extraverbal, podemos inferir a quais outros enunciados o texto responde? Com que visões ele dialoga, problematiza, se contrapõe? 5) Como que a estrutura composicional do enunciado se articula com as características do gênero do discurso? Essa articulação, de alguma forma, implica a sustentação de uma visão de ciência implícita? 6) A escolha lexical ao longo do texto evidencia, de forma explícita, a veiculação de uma visão epistemológica? Essa visão explícita está de acordo com o que foi inferido a partir da análise estrutura composicional? 7) A formação dos autores influencia na visão de ciência veiculada nos enunciados?

\section{Resultados e discussão}

No caso da presente pesquisa, podemos indicar que todos os enunciados avaliados pertencem ao mesmo gênero do discurso - texto didático. E, uma vez que todos foram submetidos e aprovados pelo mesmo edital (que exige dos livros um conjunto definido de características), podemos ser ainda mais específicos: os 14 enunciados avaliados pertencem ao subgênero de livros didáticos aprovados no PNLDEM 2015 (BRASIL, 2013). Isso significa que eles têm similaridades tanto em estrutura composicional quanto em estilo, guardadas as variações estilísticas individuais dos diferentes autores.

\section{IV.1 Identificação dos enunciados}

Em cada livro didático, identificamos que os tópicos associados à Física Quântica formam um único enunciado. Isso pode ser percebido, pois a construção composicional dos textos se dá de forma que cada seção precisa da próxima para concluir o tema que está abordando. 
Uma das características da conclusibilidade (condição para identificação dos limites do enunciado) é a exauribilidade semântica-objetal e essa só é alcançada ao fim de toda a discussão da Física Quântica, e não em cada seção interna. Dessa forma, nosso estudo analisou 14 enunciados sobre Física Quântica referente aos 14 livros didáticos aprovados no PNLDEM 2015.

\section{IV.2 Primeira leitura}

Uma vez identificados os enunciados, fizemos uma primeira leitura dos textos, já tendo em mente os conceitos da Filosofia da Linguagem de Bakhtin bem como as questões de pesquisa apresentadas na seção de introdução desse artigo. Chamou-nos atenção a semelhança entre os diferentes enunciados com relação à sua composição e estilo, além do que esperaríamos normalmente de diferentes elementos do mesmo gênero discursivo.

Nessa etapa, mapeamos os tópicos (teorias, ideias, experimentos) que são apresentados nos textos didáticos. A frequência relativa de enunciação de cada tópico está apresentada na Fig. IV.1 em termos percentuais (sendo que o valor 100\% representa que o tópico foi apresentado em todos os 14 enunciados). Alguns subtópicos foram absorvidos por ideias mais amplas (alguns textos, por exemplo, apresentam uma seção só para o átomo de Bohr, mas isso foi incluindo no tópico Modelos Atômicos).

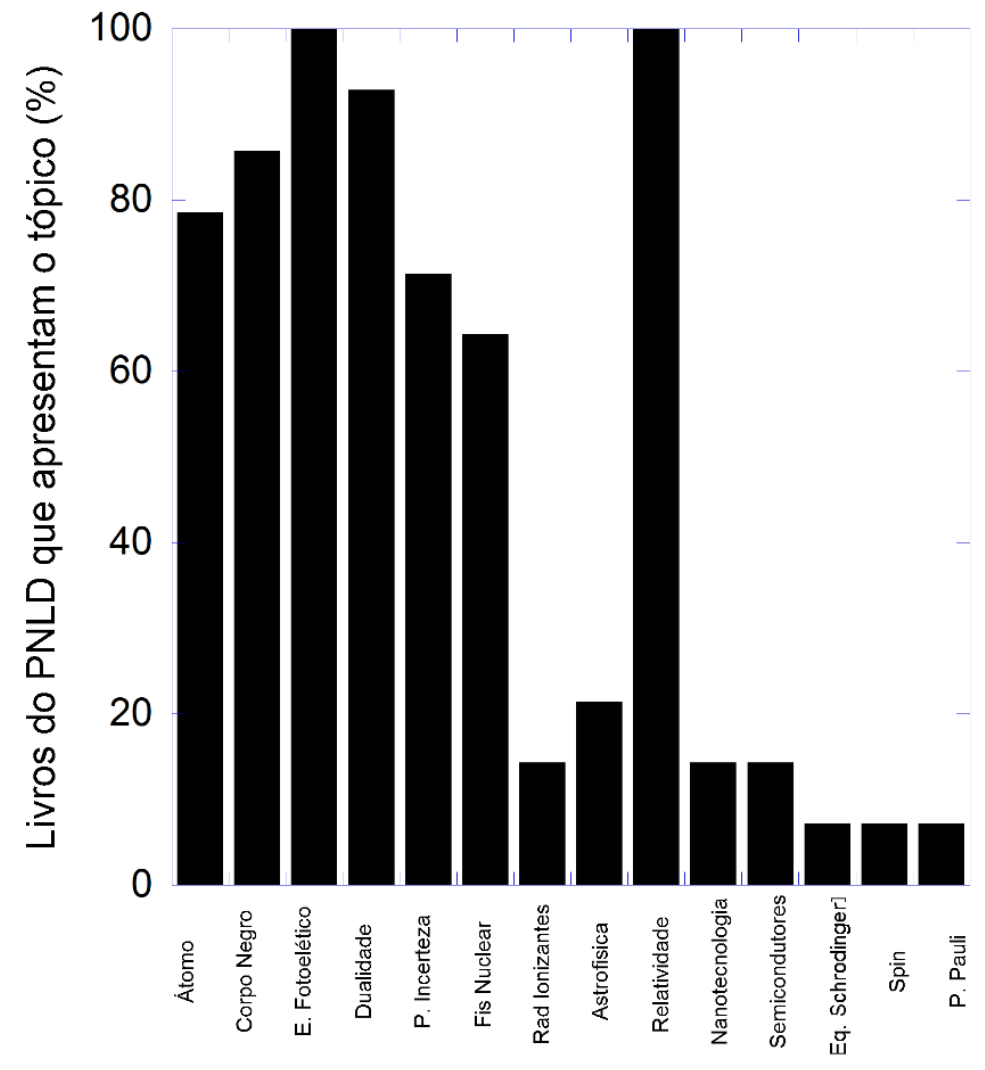

Fig. IV.1. Frequência relativa de enunciação de cada tópico em termos percentuais (sendo que o valor 100\% representa que o tópico foi apresentado em todos os 14 enunciados). 
A Fig. IV.1 evidencia a grande uniformidade com relação à estrutura composicional dos enunciados mencionada anteriormente. Todos os textos optam pela abordagem da escola espanhola, em que a Física Quântica é apresentada sob um viés histórico. Deve-se ter em mente, conquanto isso, que a história da ciência é um fenômeno extremamente complexo - existe um número muito grande de fatos históricos que a compõem e que dialogam entre si, de tal forma que não existe uma única forma de contar essa história, nem mesmo uma escolha "natural".

Ao decidir fazer um enunciado sobre a história da Física Quântica, um autor sempre terá que fazer recortes, isto é, terá que privilegiar certos fatos históricos, ideias, teorias e experimentos em detrimento de todo o resto. Apesar disso, 13 dos 14 enunciados, produzidos por diferentes locutores, apresentam quase exatamente o mesmo recorte histórico, privilegiando praticamente as mesmas ideias e cometendo, inclusive, os mesmos erros de historicidade (o que será discutido em detalhe no item 5.4).

Apesar dessa hegemonia temática, deve-se constatar que dois livros (ARTUSO; WUBLEWSKI, 2013; OLIVEIRA et al., 2013) trazem uma rápida discussão sobre o Interferômetro de Mach-Zehnder (IMZ). Essas inserções indicam um diálogo entre os enunciados dos livros didáticos e as publicações na área de Ensino de Física que trazem o IMZ como uma ferramenta para abordagem da nova FQ (SILVA NETO; CAVALCANTI; OSTERMANN, 2015; SILVA NETO; OSTERMANN; PRADO, 2011; PEREIRA; OSTERMANN; CAVALCANTI, 2009; BETZ; LIMA; MUSSATO, 2009).

\section{IV.3 Contexto extraverbal}

Para entender o contexto de produção dos enunciados, analisamos o edital do PNLD e a formação dos autores.

\section{IV.3.1 Edital do PNLDEM}

O edital do PNLDEM de 2015 (BRASIL, 2013) apresenta os requisitos necessários para que as obras sejam aprovadas e, portanto, passíveis de ser adotadas nas escolas públicas brasileiras. É importante notar que o PNLDEM surge em um contexto de reforma educacional, após a promulgação da Lei de Diretrizes e Bases em 1996. Essa reforma pós ditadura militar tentou romper (pelo menos normativamente) com pressupostos pedagógicos do período anterior, como tecnicismo, pragmatismo e comportamentalismo, os quais chegam ao Brasil por acordos de cooperação com os Estados Unidos como o MEC-USAID em 1966 (MARTINS, 2014).

Com relação à inserção de tópicos de Física Moderna e Contemporânea, da qual a Física Quântica faz parte, o PNLDEM2015 faz a seguinte exigência: “[o livro] trata de forma adequada e pertinente, considerando os diversos estudos presentes na literatura atual da área, tópicos usualmente classificados como de Física Moderna e Contemporânea e que sejam considerados importantes ou mesmo imprescindíveis para o exercício da cidadania ativa, crítica e 
transformadora, bem como para a inserção ativa, crítica e transformadora no mundo do trabalho".

Além disso, destacamos dois requisitos da ficha de avaliação que abordam as visões de ciência e interessam, portanto, a essa pesquisa: o livro "propõe discussões sobre as relações entre ciência, tecnologia, sociedade e ambiente, promovendo a formação de um cidadão capaz de apreciar e de posicionar-se criticamente diante das contribuições e dos impactos da ciência e da tecnologia sobre a vida social e individual" e o livro "utiliza abordagens do processo de construção das teorias físicas, sinalizando modelos de evolução dessas teorias que estejam em consonância com vertentes epistemológicas contemporâneas.”

De acordo com o edital, se o livro didático não atende a qualquer um dos requisitos transcritos, ele não poderia ser aprovado no PNLDEM (BRASIL, 2013).

\section{IV.3.2 Quem são os autores dos livros didáticos?}

Com base nas informações fornecidas pelos livros didáticos e pela plataforma Lattes, analisamos a formação acadêmica (graduação, mestrado e doutorado) dos autores (tabela IV.1) bem como sua produção acadêmica na área de "Ciências Exatas e da Natureza" e de Ensino de Física (tabela IV.2). Os resultados da tabela IV.1 estão em percentual com relação ao número total de autores de todos os livros (47 autores) - sendo que o somatório da primeira coluna ultrapassa $100 \%$ visto que existe uma porção significativa de autores com mais de um curso de graduação. Nenhum autor apresenta, entretanto, mais de um mestrado ou doutorado.

Tabela IV.1. Formação Acadêmica dos autores dos livros didáticos aprovados no PNLDEM 2015. Percentual dado em relação ao número total de autores. Diversos autores possuem mais de uma graduação.

\begin{tabular}{|c|c|c|c|}
\hline & Graduação & Mestrado & Doutorado \\
\hline Lic. Física & $64 \%$ & - & - \\
\hline Bac. Física & $28 \%$ & - & $4 \%$ \\
\hline Engenharia & $19 \%$ & $6 \%$ & $0 \%$ \\
\hline Pedagogia & $9 \%$ & $0 \%$ & - \\
\hline Lic. Matemática & $6 \%$ & - & - \\
\hline Bac. Matemática & $6 \%$ & - & $4 \%$ \\
\hline Outros & $6 \%$ & $4 \%$ & $4 \%$ \\
\hline Física & - & $15 \%$ & $2 \%$ \\
\hline Ensino /Educação & - & $21 \%$ & $86 \%$ \\
\hline Epistemologia & - & $4 \%$ & $50 \%$ \\
\hline Não possui & $0 \%$ & & \\
\hline
\end{tabular}


É interessante notar que uma porção significativa dos autores não possui licenciatura (36\%), metade dos autores não possui mestrado, e a grande maioria não possui doutorado $(86 \%)$. Além disso, de acordo com a tabela IV.2, podemos notar que autores de apenas 3 coleções apresentam produção significativa (mais de dez artigos) em Ensino de Física, e de 3 coleções apresentam produção significativa em Ciências Exatas e da Natureza.

Tabela IV.2. Número de artigos publicados em Física e em Ensino de Física (somatório sobre a contribuição de todos os autores por livro didático).

\begin{tabular}{|c|c|c|c|}
\hline Ref. & No $^{\text {de autores }}$ & $\begin{array}{c}\mathrm{N}^{\mathrm{o}} \text { de artigos } \\
\text { Ciências Exatas }\end{array}$ & $\begin{array}{c}\mathrm{N}^{\mathbf{o}} \text { artigos } \\
\text { Ensino }\end{array}$ \\
\hline Gaspar (2013) & 1 & 0 & 18 \\
\hline Artuso, Wublewski (2013) & 2 & 12 & 2 \\
\hline Oliveira et al. (2013) & 4 & 0 & 38 \\
\hline Yamamoto e Fuke (2013) & 2 & 0 & 0 \\
\hline Guimarães, Piqueira e Carron (2013) & 3 & 124 & 0 \\
\hline Barreto Filho e Xavier (2013) & 2 & 0 & 0 \\
\hline Luz e Álvares (2013) & 2 & 0 & 0 \\
\hline Bonjorno et al. (2013) & 6 & 0 & 0 \\
\hline Gonçalves Filho e Toscano (2013) & 2 & 0 & 4 \\
\hline Biscuola, Boas e Doca (2013) & 3 & 0 & 0 \\
\hline Menezes et al. (2013) & 6 & 0 & 81 \\
\hline Stefanovits (2013) & 6 & 48 & 1 \\
\hline Sant'Anna et al. (2013) & 4 & 6 & 0 \\
\hline Torres et al. (2013) & 4 & 0 & 0 \\
\hline
\end{tabular}

\section{IV.4 Análise Bakhtiniana}

Nessa seção, apresentamos a última etapa da análise bakhtiniana, que consiste na articulação dos conceitos da Filosofia da Linguagem, as perguntas de pesquisa e o objeto de estudo. Ao longo dessa seção, repetimos as perguntas apresentadas no item 3.4 em itálico para facilitar a leitura.

A primeira pergunta que norteou nossa análise foi com qual gênero do discurso estamos lidando. Como mencionado anteriormente, todos os enunciados analisados pertencem ao gênero discursivo livro didático, mas podemos ser ainda mais específicos, identificando-os como pertencendo ao subgênero de livros didáticos aprovados no PNLDEM 2015.

A partir disso, aprofundamos a visão sobre a relação do gênero com o auditório: a partir da definição do gênero do discurso e do conhecimento do contexto extraverbal, podemos inferir qual é o auditório do enunciado, isto é, para quais supostos interlocutores o autor fala? Os enunciados, por se tratarem de textos didáticos presentes no terceiro volume das respectivas 
coleções, têm como membros do auditório alunos do terceiro ano do Ensino Médio bem como os seus professores. Além disso, esses livros foram submetidos ao edital do PNLDEM 2015, o que indica que os locutores também tomam como auditório os avaliadores do programa. Assim, devemos ter em mente que o enunciado tem uma dupla direcionalidade: ele dialoga com membros da comunidade escolar (alunos e professores) e com membros da comunidade acadêmica, que têm por objetivo identificar se os livros atendem aos requisitos do edital em questão.

A terceira pergunta realizada foi qual o tema dos enunciados. Treze dos quatorze enunciados analisados tem como tema a origem da Física Quântica. O único livro que foge a essa classificação é o livro de Oliveira et al (2013), cujo tema é a natureza da luz. Essa distinção deve ser feita visto que os autores das trezes coleções fragmentam a Física conceitualmente, como se o estudo da Física Quântica partisse unicamente da solução do problema do corpo negro e não dialogasse com os demais conteúdos da Física, como se fosse um estudo independente e acabado em si mesmo.

Ainda que essa abordagem pareça realçar a ruptura conceitual entre Física Clássica e Quântica (conforme preconiza a escola espanhola), esse recorte muito estreito da história da ciência cria a falsa noção de que as teorias surgem do nada, por atos de genialidade, a partir da observação direta do experimento ou de um problema específico (no caso, o problema da radiação de corpo negro), sem aprofundar o contexto teórico em que as teorias são produzidas e as relações dialógicas extremamente complexas que existem na construção científica. Trata-se de uma espécie de deformação da abordagem histórica, na qual reconhecemos um forte viés positivista, visão que considera a ciência como um método neutro, fundado em conhecimento empírico e livre de metafísica (PACKER, 2011; OSTERMANN; CAVALCANTI, 2011)

Notamos que existe, apesar de se tratarem de abordagens históricas, uma diminuição ou esquecimento do papel das teorias anteriores, como nas seguintes passagens: "Para explicar a distribuição espectral da radiação térmica, Planck introduziu hipóteses totalmente novas, revolucionárias (...)" (GUIMARÃES; PIQUEIRA; CARRON, 2013). "Modificando algumas equações conhecidas à época, Planck conseguiu que as curvas teóricas e experimental coincidissem" (STEFANOVITS, 2013) Na primeira passagem, os autores falam de hipóteses totalmente novas, revolucionárias. Do ponto de vista da análise bakhtiniana, tal posicionamento é totalmente impossível: ninguém jamais consegue dizer algo totalmente novo. Ainda que se admita a existência de rupturas epistemológicas, essas não podem negar a construção da ciência, a qual se dá através do encadeamento de enunciados. De fato, é sabido que o método empregado por Planck era uma extensão do que fora desenvolvido por Boltzmann (KUHN, 1978) e, portanto, não pode ser denominado de "totalmente" novo.

Na segunda citação, o passado da Física é sintetizado na expressão "algumas equações conhecidas à época". Além de colocar toda a Física Clássica em uma "caixa preta", o locutor minimiza a complexidade do fato histórico e social que envolve o advento da Física Quântica. Deve-se lembrar que, no primeiro artigo em que Planck propôs sua equação o fez por uma interpolação dos modelos de Wien e Rayleigh e, somente depois, usou argumentos de mecânica 
estatística para derivar a mesma expressão. Quando Einstein publicou seu primeiro artigo sobre a discretização da radiação, em 1905, imaginava que o modelo de Planck era incompatível com a sua hipótese do quantum de luz (EINSTEIN, 1906). Foi somente no ano seguinte que Einstein começou a defender que o modelo de Planck conduzia à hipótese do quantum. Conquanto isso, Planck manteve-se contrário à quantização da radiação até pelo menos 1909 (EINSTEIN, 1909).

Essa fragmentação da história, nos livros didáticos, indica uma assimetria epistemológica na abordagem do tema: os autores apresentam os tópicos da Física Quântica (dentro do enunciado) sob um viés histórico (com um modelo de evolução linear), mas não colocam a própria Física Quântica num debate histórico mais amplo. Ainda que assimétricas, ambas abordagens veiculam um viés positivista, pois simplificam ao extremo as complexas relações dialógicas de construção da ciência.

A abordagem simplista sobre a História da Ciência em livros didáticos não é algo novo e configura-se como um obstáculo à inserção de História e Filosofia da Ciência no Ensino já retratado em diferentes pesquisas (MARTINS, 2007; HOTTECK; SILVA, 2011; VIDAL; PORTO, 2012). Oliveira et al. (2013) fogem dessa abordagem simplista, pois, ao falar da natureza da luz, incorporam os debates entre Newton e Huygens, Poisson e Fresnel, a busca pelo éter, a relatividade restrita e, por fim, o início da Física Quântica num único enunciado. Os outros livros fragmentam esses temas, mostrando a relatividade, por exemplo, como uma teoria alheia a esse debate (uma exceção parcial a isso é o livro de Biscuola, Boas e Doca (2013) que introduz relatividade entre as seções sobre a história da quântica, antes de entrar na teoria de De Broglie).

Outros textos mencionam a recorrência do debate entre natureza corpuscular e ondulatória da luz na história da Física, mas o fazem de maneira periférica, a título de contextualização do problema como o caso de Yamamoto e Fuke (2013) e Luz e Álvares (2013) - como se a história e a ciência não conversassem entre si. Esse tipo de contextualização simplória, não problematizada, abre uma dúvida sobre o domínio do assunto pelos próprios autores e sobre a intenção que está por trás dessa enunciação. Uma das exigências do edital é que os livros apresentem contextualização histórica, então, nessas passagens, temos a impressão de que os autores estão direcionando o enunciado aos avaliadores do PNLDEM, respondendo às exigências do edital de maneira superficial.

A partir do conhecimento extraverbal, podemos inferir a quais outros enunciados, o texto responde? Com que visões ele dialoga, problematiza, se contrapõe? Primeiramente, uma vez que os livros foram submetidos ao edital do PNLDEM, é natural esperar que eles respondam ao edital - conforme notamos já ao responder à questão 3. Além disso, vimos que a maioria dos autores não possui pós graduação em Ensino de Física ou mesmo em Física. Isso significa que, provavelmente, seu contato com Física Moderna e Física Quântica se deu em disciplinas introdutórias de graduação, em que, normalmente se usam os livros de Eisberg e Resnick (1994), Tipler e Llewellyn (2008) e Halliday e Resnick (2010). Podemos perceber que esses 
livros de graduação também seguem uma abordagem histórica, apresentando a Física Moderna sem colocá-la num contexto mais amplo na história da Física, e, por fim, também a colocam em uma sequência linear: problema do corpo negro, Efeito Fotoelétrico, Efeito Compton, dualidade de De Broglie, Equação de Schrodinger. A similaridade dos textos aprovados no PNLDEM com os livros de graduação, aliada à identificação da pouca formação dos autores na área, indica que os autores veiculam os enunciados que estudaram em sua formação, tendo apenas o cuidado de simplificar o formalismo matemático, o que se configura em uma espécie de colonialismo didático. Tal fenômeno implica uma subordinação do Ensino Básico ao Ensino Superior.

Partimos, então, para análise de um dos elementos do enunciado: Como que a estrutura composicional do enunciado se articula com as características do gênero do discurso? Essa articulação, de alguma forma, implica a sustentação de uma visão de ciência implícita? Já abordamos esse aspecto, superficialmente, na questão três. Indicamos que os livros apresentam uma assimetria em sua abordagem histórica: contam a evolução histórica da quântica a partir do problema de radiação do corpo negro, mas negam sua historicidade num contexto maior, o que reforça a ideia de uma ciência objetiva e linear. Além disso, os autores fazem da história da física a história dos experimentos - os problemas sempre começam com os experimentos, e as teorias apenas se desdobram para resolvê-los. Essa estrutura composicional, mais uma vez, veicula fortemente um viés positivista (SILVEIRA; OSTERMANN, 2002)

Além disso, ao contar a história dos experimentos, os autores negam e omitem a existência de teorias rivais que se construíram à época do desenvolvimento da Física Quântica. Na época do artigo de Einstein, que aborda o Efeito Fotoelétrico, por exemplo, o fenômeno era explicado pela Teoria do Gatilho (MARTINS; ROSA, 2014). Nenhum autor menciona essa teoria e Luz e Álvares (2013), Sant'Anna et al (2013) e Oliveira et al. (2013) dizem que não havia explicação na época. Nenhum autor comenta, também, que ao longo do desenvolvimento da Quântica, desenvolveram-se teorias ondulatórias para explicar o Efeito Fotoelétrico e Compton (GREENSTEIN; ZAJONE, 2006). Mais uma vez, essa opção de construção da história privilegiando apenas as teorias hegemônicas fortalece a visão positivista da ciência.

Ainda, alguns livros cometem erros de historicidade - afirmando explicitamente, por exemplo, que Einstein partiu do modelo de Planck para propor o Efeito Fotoelétrico, enquanto, de fato, ele parte do modelo de Wien (anterior ao de Planck) e reconhece que sua hipótese poderia ser válida somente para pequenos comprimentos de onda (EINSTEIN, 1905). A derivação a partir de um modelo anterior ao de Planck é negada pelos autores para salvar a linearidade objetiva da ciência, e a limitação do modelo descrita por Einstein é omitida para salvar o status hegemônico da ciência como forma de produção de conhecimento absoluto.

Os livros didáticos trazem a história da ciência apenas como contextualização no início da seção, situando o aluno em termos de datas, mas não mostram como os conceitos são construídos dentro dessa historicidade. Existe uma desconexão entre história da física e a física como se a ciência, ainda que situada na história, lhe fosse totalmente alheia. 
Além disso, a visão de uma ciência supostamente objetiva motiva a apresentação de uma abordagem ingênua da interação ciência, tecnologia e sociedade - reforçando o mito da linearidade: ciência sempre promove avanço tecnológico, que sempre promove bem-estar social (DECONTO, 2014). Destacamos alguns trechos cuja expressividade se mostra otimista e ingênua com relação ao papel da ciência na sociedade: "Essa compreensão do mundo subatômico levou ao desenvolvimento, por exemplo, da nanotecnologia. (...) Que dispositivos não existiriam sem os conhecimentos disponíveis sobre o mundo subatômico?" (MENEZES et al., 2013, p. 214) "A Física quântica tem proporcionado um desenvolvimento tecnológico sem precedentes (...)." (GUIMARÃES; PIQUEIRA; CARRON, 2013, p. 212). "O efeito fotoelétrico tem aplicação, por exemplo, na contagem de pessoas que passam por um local (...)" (BISCUOLA; BOAS; DOCA, 2013, p. 271 ). "Neste capítulo, vamos estudar o que isso tem a ver com o aparelho de TV, com a máquina fotográfica, com o aparelho de DVD ou Blu-ray e toda uma infinidade de equipamentos que a Física Quântica permitiu desenvolver." (BONJORNO et al., 2013, 241). "Sabemos que a ciência progride em complexidade e tecnologia à medida que novas ideias surgem, geralmente a partir de outras mais antigas e comumente mais simples." (GONÇALVES FILHO; TOSCANO, 2013, p.164). “Assim como em outras áreas da Física, as pesquisa teóricas no campo da Física Moderna também vem contribuindo para o desenvolvimento tecnológico. O estudo do mundo microscópico possibilitou criar equipamentos que podem ser utilizados em diferentes áreas." (GONÇALVES FILHO; TOSCANO, 2013, p. 165). "Assim como ocorria em outras áreas do conhecimento da Física, o conhecimento científico desenvolvido durante a elaboração da Física Quântica também possibilitaria a produção de tecnologia em diferentes áreas do cotidiano" (GONÇALVES FILHO; TOSCANO, 2013, p. 168). "Os avanços tecnológicos dos últimos cem anos que revolucionaram a vida e os costumes da humanidade no século XX foram, em grande parte, frutos das aplicações dos conceitos da nova Física do mundo da partículas subatômicas." (TORRES et al., 2013, p. 235). "Inúmeras aplicações desse efeitos estão presentes em nosso dia a dia" ( SANT'ANNA et al., 2013. p. 260).

Deve-se comentar que essa percepção simplista das interações entre ciência, tecnologia e sociedade, promovendo um clima ufanista com relação aos benefícios da ciência e do mundo "moderno" pode ser considerada uma característica do ensino tecnicista (típico do paradigma educacional do período da ditadura militar) que visava promover a formação de mão de obra para o processo de industrialização nacional (MARTINS, 2014).

Seguindo a análise dos elementos do enunciado e sua relação com a visão de ciência veiculada, partimos para análise de escolha de palavras e expressões: a escolha lexical ao longo do texto evidencia, de forma explícita, a veiculação de uma visão epistemológica? Essa visão explícita está de acordo com o que foi inferido a partir da análise da estrutura composicional?

Os livros, com exceção de Oliveira et al. (2013), veiculam fortemente um viés positivista, primeiramente, por sua estrutura composicional - tanto pelo que optam apresentar, mas também pelo que optam omitir - conforme discutimos na questão anterior. Além disso, em frequências diferentes, podemos encontrar em todos os quatorzes enunciados expressões típicas 
que podemos associar ao viés positivista. Deve-se notar que essa veiculação positivista pela escolha lexical é um indício sutil se analisado isoladamente, mas quando considerado a partir da totalidade do enunciado, em que a estrutura composicional já corrobora a visão positivista, vemos que essa escolha lexical fortalece o viés epistemológico que está sendo veiculado. Selecionamos alguns exemplos: "O significado das linhas espectrais estava assim desvendado" (MENEZES et al., 2013, p. 220). “A comprovação experimental da teoria de De broglie foi obtida em 1927, tendo por base o experimento de dupla fenda para a radiação eletromagnética realizado por Thomas Young (1773-1829)." (STEFANOVITS, 2013, p. 250) "Com a confirmação da hipótese de De broglie, ficava estabelecida a dualidade onda-partícula." (ARTUSO; WRUBLEWSKI, 2013, p 278). “O trabalho de Einstein mostrou que o efeito fotoelétrico não pode ser interpretado com base no modelo ondulatório da luz" (GUIMARÃES; PIQUEIRA; CARRON, 2013, p. 217). "Experiências como o efeito fotoelétrico e o efeito Compton (...) demonstraram que a luz pode também se comportar como partícula." (GUIMARÃES; PIQUEIRA; CARRON, 2013, p.225). "Em 1927, a teoria de De Broglie foi confirmada pela primeira vez, em um experimento no qual se determinou o comprimento de onda de elétrons que sofrem difração." (BISCUOLA; BOAS; DOCA, 2013, p. 292). "Estudos mais detalhados do fenômeno de Hertz revelaram que, a centelha realmente se tornava maior." (BONJORNO et al., 2013, p. 247). "Em 1923, Arthur Holly Compton (1892-1962) físico estadunidense, comprovou experimentalmente a natureza quântica dos raios X. (BONJORNO et al., 2013. p. 253). O Efeito Compton confirma que os fótons se comportam como partículas(...)" (BONJORNO et al., 2013, p. 247). “As ideias de De Broglie tiveram confirmação nas experiências realizadas em 1927 pelos físicos estadunidenses (...)." ((BONJORNO et al., 2013, p. 254). "Essa hipótese, hoje já plenamente confirmada (...)" (TORRES et al., 2013, p. 235). “(..) confirmando experimentalmente a teoria do físico francês (TORRES et al., 2013, p. 251). A explicação correta para o efeito fotoelétrico foi dada por Albert Einstein." (TORRES et al., 2013, p. 242). "O resultado do experimento de Young comprovou definitivamente que a luz tem caráter ondulatório" (SANT’ANNA et al., 2013, p. 255). "Essa teoria foi tomando formato aos poucos, sendo construída por vários cientistas à medida que solucionavam os problemas originados pelas experiências" (LUZ; ALVARES, 2013, p. 295). "O surgimento da Física Quântica, a partir de experiências, foi diferente do surgimento da teoria da relatividade(...)" (LUZ; ALVARES, 2013, p. 295). "A Física quântica aos poucos foi revelando certos comportamentos estranhos da natureza." (LUZ; ALVARES, 2013, p. 295). "Em 1927, experiências de difração foram efetuadas com elétrons, comprovando a hipótese de De Broglie.” (LUZ; ALVARES, 2013, p. 302). "Finalmente, em 1928, o físico Max Born descobriu uma relação entre a função de onda e a probabilidade de se encontrar a partícula." (LUZ; ALVARES, 2013, p. 303)

Diferentemente da visão positivista, a qual é o posicionamento epistemológico predominante nos livros didáticos, podemos encontrar apenas uma passagem com viés popperiano 
(SILVEIRA, 1996; SILVEIRA; OSTERMANN, 2002): “Contudo novas evidências da quantização da luz e da energia surgiram logo depois, de modo que a teoria fosse cada vez mais aceita." (STEFANOVITS, 2013, p. 248)

Apesar dessa forte veiculação positivista nos enunciados, mais uma vez, podemos notar que existem momentos em que os autores dialogam com os avaliadores, buscando o preenchimento dos requisitos do edital. O trecho abaixo aponta uma virada repentina de viés epistemológico, em que os autores reconhecem o lado social da ciência, o qual é negado na maior parte do enunciado: “(...) pois a Física Quântica também foi influenciada pelo contexto histórico da época de sua reformulação (...)" (STEFANOVITS, 2013, p. 251).

O enunciado de Gonçalves Filho e Toscano (2013) é um dos que apresenta a interação ciência, tecnologia e sociedade pelo mito CTS (conforme trechos apresentados no item anterior), chegando a afirmar que teorias antigas são mais simples, contraditoriamente - o enunciado apresenta um quadro sobre a epistemologia de Thomas Kuhn (cujo conceito de incomensurabilidade vai de encontro à comparação da complexidade entre teorias) e um quadro sobre o papel das mulheres na ciência, que não dialogam em nada com o restante do texto. Mais uma vez, entendemos que esse enunciado se direciona aos avaliadores e não aos alunos.

Feita a análise dos elementos verbais do enunciado, retomamos o problema do contexto extra verbal: A formação dos autores influencia na visão de ciência veiculada nos enunciados? O único enunciado que não veicula uma visão positivista em sua estrutura composicional e tema é o contido no livro Física Conceitos e Contextos (OLIVEIRA et. al, 2013), cujo primeiro autor tem doutorado em epistemologia e história da ciência. Tal fato sugere que a falta de formação em epistemologia implica uma possível falta de crítica com relação à veiculação de visões ultrapassadas de ciência.

\section{Conclusões}

Apresentamos nesse artigo uma análise bakhtiniana dos enunciados de Física Quântica nos catorze livros didáticos aprovados no PNLDEM 2015. Nessa análise, investigamos as abordagens apresentadas, os conceitos, as teorias e os experimentos que são privilegiados e as visões de ciência que são veiculadas.

Nossos resultados indicam que todos os livros optam por introduzir a FQ em uma perspectiva histórica, evidenciando os limites dos modelos clássicos e se restringindo à velha FQ. Um livro se destaca por trazer essa discussão em um domínio temporal mais amplo, ao longo da história da Física (esse livro foi escrito pelo único autor com doutorado em Epistemologia e História da Ciência). Esse livro usa a natureza da luz como fio condutor da discussão, integrando diferentes teorias, experimentos e movimentos científicos. Os demais livros apresentam uma visão histórica fragmentária e linear, identificando o desenvolvimento da física moderna como um acúmulo de visões. Nessa abordagem histórica, os autores identificam a história da física como a história dos experimentos (indutivismo ingênuo) e omitem a existência 
de teorias rivais, que concorreram ao longo do desenvolvimento da Física Moderna e de limitações nos modelos. Essa abordagem simplista e ingênua veicula implicitamente um viés positivista, o que é combatido por todas escolas epistemológicas contemporâneas.

Além disso, identificamos que os tópicos mais presentes nos livros didáticos do PNLDEM 2015 são os mesmos presentes em livros didáticos usados no Ensino Superior. Considerando que a maioria dos autores não tem uma formação em Física Moderna e Contemporânea além da graduação, supõe-se que esses se inspiraram em sua própria formação para a escrita dos livros didáticos, cometendo inclusive os mesmos erros de historicidade dos livros usados no Ensino Superior.

Mostramos, também, que os autores utilizam, em diferentes frequências, construções frasais que expressam explicitamente uma visão positivista e uma visão ingênua das interações ciência, tecnologia e sociedade. Alguns livros, entretanto, apresentam trechos com uma visão epistemológica contrária ao que veicula no restante do enunciado. Essas variações foram interpretadas como uma tentativa de atender aos requisitos estabelecidos pelo PNLDEM 2015 de forma simplista e superficial. Ao atender tais requisitos, os livros aprovados pelo PNLDEM garantem às editoras a participação em um projeto bilionário. No caso específico do PNLDEM 2015, por exemplo, o governo gastou em aquisição de livros didáticos mais de um bilhão e cem milhões de reais (BRASIL, 2017).

Dessa forma, pode-se notar que, apesar do PNLDEM tentar afastar do ensino tecnicista, os livros didáticos aprovados não rompem com esse paradigma didático proveniente do período da ditadura militar, silenciando discussões filosóficas e críticas em benefício de um ensino simplista, pragmatista e ingênuo. O Ensino de Física Quântica nos livros didáticos, portanto, é, ainda subserviente a um projeto político-social que visava atender a demandas da industrialização (no período de 60-80) e posicionar o Brasil no eixo capitalista durante a Guerra Fria (MARTINS, 2014).

Por fim, os livros aprovados no PNLDEM 2015 ainda representam uma produção didática dissonante em relação aos avanços epistemológicos contemporâneos e aos resultados da pesquisa em Ensino de Física. Faz-se compulsório uma nova visão sobre o ensino de Física Quântica no Ensino Médio, que privilegie discussões epistemológicas e conceituais. Uma possível alternativa é adotar uma abordagem da FQ, a partir do Interferômetro de Mach-Zehnder, utilizado como ferramenta mediacional, como já vem apontando a literatura recente.

\section{Referências}

ARONS, A. B. A guide to introductory physics teaching. New York: John Wiley, 1990.

ARTUSO, A. R.; WRUBLEWSKI, M. Física. Curitiba: Positivo, 2013.

BAKHTIN, M. Os gêneros do discurso. São Paulo: Editora 34, 2016.

BAKHTIN, M. Marxismo e Filosofia da Linguagem. 12. ed. São Paulo: HUCITEC, 2006. 
BARRETO FILHO, B.; XAVIER, C. Física aula por aula: eletromagnetismo, ondulatória e física moderna: $3^{\circ}$ ano. São Paulo: FTD, 2013.

BETZ, M.; LIMA, I.; MUSSATO, G. Dualidade onda-partícula: um objeto de aprendizagem baseado no interferômetro de Mach-Zehnder. Revista Brasileira de Ensino de Física, v. 31, n. 3, p. 3501-3508, 2009.

BISCUOLA, G. J.; BOAS, N. V.; DOCA, R. H. Física 3. 2. ed. São Paulo: Saraiva, 2013.

BONJORNO, J. R. et al. Física: eletromagnetismo, física moderna - $3^{\circ}$ ano. 2. ed. São Paulo: FTD, 2013.

BRASIL. Edital do PNLD. 2013. Disponível em: <www.fnde.gov.br/programas/livro-didatico/livro-didatico-editais $>$.

BRASIL. Dados Estatísticos PNLD. Disponível em: < http://www.fnde.gov.br/programas/livro-didatico/livro-didatico-dados-estatisticos>. Acesso em: 23 jun. 2017.

DECONTO, D. C. S. A perspectiva Ciência Tecnologia e Sociedade na disciplina Metodologia do Ensino de Física: um estudo na formação de professor à luz do referencial sociocultural. 2014. 442p. Dissertação (Mestrado em Ensino de Física) - Instituto de Física, Universidade Federal do Rio Grande do Sul, Porto Alegre.

DOMINGUINI, L. Questões históricas da evolução da Física Moderna nos livros didáticos de Física do PNLEM. Vidya, v. 31, n. 2, p. 11-26, 2011.

DOMINGUINI, L. Física moderna no Ensino Médio: com a palavra os autores dos livros didáticos do PNLEM. Revista Brasileira de Ensino de Física, v. 34, n. 2, p. 1-7, 2012.

EINSTEIN, A. Concerning an heuristic point of view toward the emission and transformation of light. Einstein Collected Papers, v. 2, p. 86, 1905. Disponível em: <http://einsteinpapers.press.princeton.edu/vol2-trans/100>. Acesso em: 08 fev. 2017.

EINSTEIN, A. On the theory of light production and light absorption. Einstein Collected Papers, v. 2, p. 192, 1906. Disponível em: <http://einsteinpapers.press.princeton.edu/vol2trans/206>. Acesso em: 08 fev. 2017.

EINSTEIN, A. On the development of our views concerning the nature and constitution of radiation. Einstein Collected Papers, v. 2. p. 379, 1909. Disponível em: <http://einsteinpapers.press.princeton.edu/vol2-trans/393>. Acesso em: 08 fev. 2017.

EISBERG, R., RESNICK, R. Física Quântica: Átomos, Moléculas, Sólidos, Partículas. 9. ed. Rio de Janeiro: Editora Campus, 1994.

FISCHLER, H., LICHTFELDT, M. Modern physics and students' conceptions. International Journal of Science Education, v. 14, n. 2, p. 181-190, 1999. 
GASPAR, A. Compreendendo a Física. 2. ed. São Paulo: Ática, 2013. v. 3.

GIL, D. P.; SENENT, F.; SOLBES, J. Análisis critico de la introducción de la física moderna en la enseñanza media. Revista de Enseñanza de la Física, v. 2, n. 1, p. 16-21.

GONÇALVES FILHO, A.; TOSCANO, C. Física: Interação e Tecnologia. São Paulo: Leya, 2013. v. 3

GRECA, I. M.; MOREIRA, M. A.; HERSCOVITZ, V. Uma proposta para o Ensino de Mecânica Quântica. Revista Brasileira de Ensino de Física, v. 23, n. 4, p. 444-457, 2001.

GREEnsteIN, G.; ZAJONE, A. G. The Quantum Challenge - Modern Research on the Foundation of Quantum Mechanics. Sudbury: Jones and Bartlett Publishers, 2006.

GUIMARÃES, O.; PIQUEIRA, J. R.; CARRON, W. Física. São Paulo: Ática, 2013.

HALLIDAY, D.; RESNICK, R. Fundamentos de Física. 8. ed. Rio de Janeiro: LTC, 2010. v. 4.

HILGER, T. R.; GLIEBER, A. Uma proposta de unidade de ensino potencialmente significativo utilizando mapas conceituais. Investigações em Ensino de Ciências, v. 18, n. 1, p. 199213, 2013.

HILGER, T. R.; MOREIRA, M. A. A study of social representations of Quantum Physics held by High School students through Numerical and Written Word Association Tests. Revista Electronica de Investigación en Educación en Ciencias, v. 8, n. 1, p. 52-61, 2012.

HOTTECKE. D.; SILVA. C. Why implementing history and philosophy in school science education is a challenge: an analysis of obstacles. Science \& Education, v. 20, n. 3-4, p. 293 $316,2011$.

JOHANSSON, A. et al. "Shut up and calculate": the available discursive positions in quantum physics courses. Cultural Studies of Education Science, 2016. Disponível em: <http://dx.doi.org/10.1007/s11422-016-9742-8>. Acesso em: 08 fev. 2017.

KUHN, T. Black-Body Theory and the Quantum Discontinuity: 1894-1912. Oxford: Oxford University Press, 1978.

LOBATO, T; GRECA, I. M. Análise da inserção de conteúdos de Teoria Quântica nos currículos de Física do ensino médio. Ciência e Educação, v.11, n.1, p. 119-132, 2005.

LUZ, A. M. R.; ALVARES, B. A. Física contexto \& aplicações. São Paulo: Scipione, 2013.

MARTINS, A. A. Artefato da Cultura Escolar ou Mercadoria? A escolha do Livro Didático de Física em Análise. 2014. 224p. Tese (Doutorado em Educação) - Setor de Educação, Universidade Federal do Paraná, Curitiba. 
MARTINS, R. A.; ROSA, P. S. História da teoria quântica: a dualidade onda-partícula, de Einstein a De Broglie. São Paulo: Editora Livraria da Física, 2014.

MARTINS, A. F. História da ciência no ensino: há muitas pedras nesse caminho. Caderno Brasileiro de Ensino de Física, v. 24, n. 1, p. 112-131, 2007.

MATTHEWS, M. R. História, filosofia, e ensino de ciências: a tendência atual de reaproximação. Caderno Catarinense de Ensino de Física, v. 12, n. 3, p. 164-214, 1995.

MAXIMIANO, J. R.; CARDOSO, L.; DOMINGUINI, L. Aspectos metodológicos do conteúdo física moderna nos livros didáticos do PNLD 2012. Revista Técnico-Científica (IFSC), v. 3, n. 1, p. 494-503, 2012a.

MAXIMIANO, J. R.; CARDOSO, L.; DOMINGUINI, L. Estruturação do conteúdo Física Moderna nos livros didáticos do PNLD2012. In: SEMINÁRIO DE PESQUISA, EXTENSÃO E INOVAÇÃO DO IF-SC, 1, 2012b, Campus Criciúma.

MAXIMIANO, J. R.; CARDOSO, L.; DOMINGUINI, L. Física Moderna nos livros didáticos: um contraponto entre o PNLEM 2009 e o PNLD 2012. Vidya, v. 33, p. 97-115, 2013.

MCCOMAS, W, F.; ALMAZROA, H.; CLOUGH, M. The nature of science in science education: an introduction. Science \& Education, v. 7, p. 511-532, 1998.

MENEZES, L. C. et al. Quanta Física. $3^{\circ}$ ano. São Paulo: Pearson Education do Brasil, 2013.

OLIVEIRA, M. P. P. et al. Física, conceitos e contextos: pessoal, social e histórico, eletricidade e magnetismo, ondas eletromagnéticas, radiação e matéria. São Paulo: FTD, 2013.

OSTERMANN, F.; MOREIRA, M. A. Uma revisão bibliográfica sobre a área de pesquisa Física Moderna e Contemporânea no ensino médio. Investigações em Ensino de Ciências, v. 5, n. 1, p. 23-48, 2000.

OStermanN, F.; CAVAlCANTI, C. Epistemologia. Porto Alegre: Evangraf; UFRGS. 2011.

PACKER, M. J. The science of qualitative research. New York: Cambridge University Press, 2011.

PEGLIARINI, C. R.; ALMEIDA, M. J. P. M. Leituras por alunos do ensino médio de textos de cientistas sobre o início da física quântica. Ciência e Educação. v. 22, n. 2, p. 299-317, 2016.

PEREIRA, A. P.; OSTERMANN, F. Sobre o ensino de Física Moderna e Contemporânea: Uma revisão da Produção Acadêmica Recente. Investigações em Ensino de Ciências. v. 14, n. 3, p. 393-420, 2009. 
PEREIRA, A. P.; OSTERMANN, F.; CAVALCANTI, C. J. H. Um exemplo de "distribuição social da mente" em uma aula de física quântica. Ciência \& Educação, v. 18, n. 2, p. 257-270, 2012.

PEREIRA, A. P.; OSTERMANN, F.; CAVALCANTI, C. J. H. On the use of a virtual MachZehnder interferometer in the teaching of quantum mechanics. Physics Education (Bristol. Print), v. 44, n. 3, p. 281-291, 2009.

SALES, G. L. et al. Atividades de modelagem exploratória aplicada ao ensino de física moderna com a utilização do objeto de aprendizagem pato quântico. Revista Brasileira de Ensino de Física, v. 30, n. 3, 2008.

SANT’ANNA, B. Conexões com a Física. São Paulo: Moderna, 2013

SANTOS, C. A. B. D.; CURI, E. A formação dos professores que ensinam física no ensino médio. Ciência \& Educação, v. 18, p. 837-849, 2012.

SILVA, A. C.; ALMEIDA, M. J. P. M. Física Quântica no Ensino Médio: O que Dizem as pesquisas. Caderno Brasileiro de Ensino de Física. v. 28, n. 3, p. 624-652, 2011.

SILVA NETO, J.; CAVALCANTI, C. J. H.; OSTERMANN, F. Estratégias discursivas adotadas por professores em formação na compreensão do fenômeno da complementaridade em atividades didáticas mediadas pelo interferômetro virtual de Mach-Zehnder. Revista Brasileira de Pesquisa em Educação em Ciências, v. 15, p. 293-320, 2015.

SILVA NETO, J.; OSTERMANN, F.; PRADO, S. D. O tema da dualidade onda-partícula na educação profissional em radiologia médica a partir da simulação do interferômetro de MachZehnder. Revista Brasileira de Ensino de Física, v. 33, n. 2, p. 01-10, 2011.

SILVEIRA, F. A Filosofia da Ciência de Karl Popper: o Racionalismo Crítico. Caderno Catarinense de Ensino de Física, v. 12, n. 3, p. 197-218, 1996.

SILVEIRA, F. L.; OSTERMANN, F. A insustentabilidade da proposta indutivista de "descobrir a lei a partir de resultados experimentais". Caderno Brasileiro de Ensino de Física, v. 19, n. especial, p. 7-27, 2002.

SOUZA, J.; REZENDE, F.; OSTERMANN, F. Apropriação discursiva de modelos de formação docente em trabalhos de conclusão de um mestrado profissional em ensino de física. Ensaio: Pesquisa em Educação em Ciências, v. 18, n. 2, p. 171-200, 2016.

SOUZA, G. T. Introdução à teoria do enunciado concreto do círculo Bakhtin/Volochinove/Medvedev. 2. ed. São Paulo: Humanitas/FFLCH/USP, 2002.

STEFANOVITS, A. (Editor responsável). Ser protagonista: Física. $1^{\circ}$ ano: ensino médio. 2. ed. São Paulo: Edições SM, 2013. 
TELICHEVESKY, L. Uma perspectiva sociocultural para introdução de conceitos de Física Quântica no Ensino Médio: Análise das interações discursivas em uma unidade didática centrada no uso do interferômetro virtual de Mach-Zehnder. 2015. 192p. Dissertação (Mestrado em Ensino de Física) - Instituto de Física, Universidade Federal do Rio Grande do Sul, Porto Alegre.

TIPlER, P.; LLEWELlyn, R. A. Modern Physics. 6. ed. New York: W. H. Freeman and Company, 2008.

TORRES, C. M. A. et al. Física Ciência e tecnologia. 3. ed. São Paulo: Moderna, 2013.

TRINDADE, J.; FIOLHAIS, C.; GIL, V. Atomic orbitals and their representation: Can 3-D computer graphics help conceptual understanding? Revista Brasileira de Ensino de Física, v. 27, n. 3, p. 319-325, 2005.

VENEU, A. A.; FERRAZ, G.; REZENDE, F. Análise de discursos no ensino de ciências: considerações teóricas, implicações epistemológicas e metodológicas. Ensaio: Pesquisa em Educação em Ciências, v. 17, n. 1, p. 126-149, 2015.

VIDAL, P. H. O.; PORTO, P. A. A história da ciência nos livros didáticos de química do PNLEM 2007. Ciência \& Educação, v. 18, n. 2, p. 291-308, 2012.

VOLOSHINOV, V. N. A estrutura do enunciado. Tradução: Ana Vaz, para fins didáticos. Texto de circulação acadêmica, 1981. [Texto original publicado na revista Literaturnja Ucëba, v. 3. p. $65-87,1930$.

WERTSCH, J. V. Voices of the mind: a socialcultural approach to mediated action. Cambridge: Harvard University Press, 1991.

YAMAMOTO, K. FUKE, L. F. Física para o Ensino Médio 3. São Paulo: Saraiva, 2013. 